\title{
Gradiente estrutural no componente arbóreo e relação com inundações em uma floresta ribeirinha, rio Uruguai, sul do Brasil
}

\author{
Eduardo Luís Hettwer Giehl ${ }^{1,3}$ e João André Jarenkow²
}

Recebido em 17/04/2007. Aceito em 27/09/2007

\begin{abstract}
RESUMO - (Gradiente estrutural no componente arbóreo e relação com inundações em uma floresta ribeirinha, rio Uruguai, sul do Brasil). O objetivo do presente estudo foi realizar uma análise exploratória de padrões estruturais e de diversidade, relacionando-os com variáveis ambientais em uma área de floresta ribeirinha. A amostra 100 unidades amostrais (UAs), foi alocada nas margens do rio Uruguai, Parque Estadual do Turvo, Rio Grande do Sul (2709' S e 535' W). Todos os indivíduos arbóreos com PAP $\geq 15$ cm foram registrados. Para a descrição da vegetação foram estimados os principais parâmetros fitossociológicos, além do índice de diversidade de Shannon. Foram mensuradas variáveis ambientais edáficas, topográficas e a cobertura do dossel. As relações entre a abundância das espécies nas UAs e as variáveis ambientais foram avaliadas por meio de análises de correspondência canônica - CCA e CCA "parcial”. Foram encontradas 82 espécies pertencentes a 30 famílias. A CCA exibiu um gradiente vegetacional nítido, relacionado hierarquicamente com a cota de elevação e, assim, com a suscetibilidade à inundação dos diferentes sítios. Três grupos de UAs foram delimitados por análise de agrupamento em função da cota de elevação e conseqüentemente suscetibilidade às inundações. Entre os grupos ocorreram diferenças estruturais, com maior área basal e altura máxima medianas nos sítios de elevação intermediária. A seletividade causada pelas inundações freqüentes sobre a composição de espécies modela a estrutura das áreas baixas, sendo a ausência de um dossel florestal típico, com no mínimo $10 \mathrm{~m}$ de altura, a característica mais expressiva. As áreas altas assemelham-se estruturalmente à floresta de interflúvio, compondo um trecho de transição. A diversidade medida pela riqueza específica e pelo índice de Shannon foi maior para áreas de elevação média, correspondendo com modelos existentes que associam a presença de um regime de distúrbios moderado, que gera maior heterogeneidade ambiental e, assim, diversificação de oportunidades para as espécies.
\end{abstract}

Palavras-chave: análise de correspondência canônica parcial, autocorrelação espacial, Floresta Estacional, Parque Estadual do Turvo, topografia

\begin{abstract}
Structural gradient of the tree component and relationship with flooding in a riverine forest, Rio Uruguai, southern Brazil). We carried out an exploratory analysis of structural and diversity patterns and related them to environmental variables in a riverine forest. The sample, divided into 100 subplots, was placed on the banks of the Rio Uruguai, Turvo State Park, Southern Brazil $\left(27^{\circ} 09^{\prime} \mathrm{S} ; 53^{\circ} 53^{\prime} \mathrm{W}\right)$. All trees with the perimeter at breast height $\geq 15 \mathrm{~cm}$ were recorded. Vegetation description was based on phytosociological parameters and Shannon's diversity index. We measured edaphic and topographic environmental variables as well as canopy coverage. The relationship between species abundance in the subplots and environmental variables was assessed by canonical correspondence analysis - CCA and "partial" CCA. We found 82 species belonging to 30 families. The CCA showed a clear gradient, related hierarchically to mean elevation and thus to flooding susceptibility at different sites. Three groups of subplots were identified by cluster analysis based on mean elevation and flooding susceptibility. There were structural differences among these groups, with the highest basal area and maximum height medians at the middle elevation sites. Selectivity caused by frequent flooding on the species pool affects structure at the lower sites, with the most surprising difference being the lack of a typical forest canopy at least $10 \mathrm{~m}$ tall. On the other hand, the upper sites are structurally similar to interfluvial forest, thus constituting a transitional section. Diversity measured by species richness and by Shannon's index was higher for middle elevation sites. This pattern fits proposed models that relate moderate disturbance regime to the generation of environmental heterogeneity, and thus, opportunities of diversification for species.
\end{abstract}

Key words: partial canonical correspondence analysis, spatial autocorrelation, Seasonal Forest,Turvo State Park, topography

\section{Introdução}

As florestas ribeirinhas são entendidas como formações adjacentes a cursos d'água e são ambientes geralmente marcados pela exposição a inundações
(Naiman et al. 1998; Rodrigues 2001), englobando áreas que contribuem com matéria orgânica ou determinam a disponibilidade de luz para as áreas inundáveis (Naiman \& Décamps 1997). Variações topográficas podem conduzir a alterações na intensidade e freqüência local

\footnotetext{
1 Universidade Federal do Rio Grande do Sul, Programa de Pós-Graduação em Botânica, Av. Bento Gonçalves 9500, Prédio 43433, $91105-970$ Porto Alegre, RS, Brasil

2 Universidade Federal do Rio Grande do Sul, Departamento de Botânica, Av. Bento Gonçalves 9500, Prédio 43433, $91105-970$ Porto Alegre, RS, Brasil

3 Autor para correspondência: eduardohet@yahoo.com.br
} 
do alcance da coluna d'água, gerando zoneamentos na vegetação (Damasceno Junior et al. 2005) ou mosaicos, ambos com elevada riqueza florística e alta diversidade (Naiman et al. 1998; Rodrigues \& Shepherd 2001).

Devido principalmente à alta heterogeneidade na distribuição espacial e temporal dos distúrbios naturais, notadamente as inundações, as florestas ribeirinhas possuem uma flora com diferentes níveis de adaptação a estes eventos (Blom \& Voesenek 1996; Naiman \& Décamps 1997; Nilsson \& Svedmark 2002). Contudo, a composição florística destes ambientes não depende exclusivamente dos distúrbios naturais, mas também da sua interação com as características edáficas e com os processos biológicos relativos à sucessão vegetal em cada sítio (Naiman et al. 1998). De acordo com Perry et al. (2002), padrões espaciais heterogêneos de abundância das espécies podem ser gerados pela disponibilidade de recursos, embora a inferência de fatores geradores deva ser considerada com cautela. Segundo Ives \& Klopper (1997), associações consistentes entre a distribuição de abundância das espécies e fatores geradores são mais evidentes em gradientes, confundindo-se com efeitos estocásticos temporais em ambientes homogêneos. Suzuki et al. (2002) afirmam que ainda não é bem esclarecido como diferenças nas condições dos sítios de estabelecimento e no regime de distúrbios entre florestas ribeirinhas e outras tipologias interagem e afetam a composição de espécies e os padrões de diversidade. Como consequiência direta, a delimitação das florestas ribeirinhas é difícil no contato destas com florestas de interflúvio.

No Parque Estadual do Turvo a matriz florestal é essencialmente a Floresta Estacional Decidual, constituindo um dos maiores fragmentos ainda existentes desta tipologia florestal no sul do Brasil (SEMA 2005). A vegetação do Parque foi estudada por vários autores com diferentes enfoques. A flora foi relatada inicialmente por Rambo (1935) e Klein (1972) e abordada em termos fitogeográficos, com a descrição das prováveis rotas de migração das espécies por Rambo (1961). Brack et al. (1985) listaram a ocorrência de 727 espécies vasculares, associando observações referentes à distribuição destas nos diferentes ambientes do Parque. Até o momento, apenas o trabalho de Vasconcellos et al. (1992) abordou a estrutura do componente arbóreo no local, embora existam outros em andamento. Nenhum trabalho foi efetuado visando a descrição qualitativa e quantitativa da vegetação de transição entre floresta ribeirinha e de interflúvio às margens do rio Uruguai, sul do Brasil. O estudo deste ecótono é importante devido à ameaça dos ambientes ribeirinhos da região pela construção de hidrelétricas (SEMA 2005) e à carência de dados para a restauração de ambientes semelhantes na região.
Além de descrever a estrutura do componente arbóreo perpendicular ao rio Uruguai, o presente estudo também levantou as seguintes questões: existem variações vegetacionais nítidas na formação florestal? Se existem, essas podem ser previstas com base em variáveis edáficas, topográficas e da cobertura do dossel? A estrutura espacial da vegetação permite inferir a existência de autocorrelação espacial?

\section{Material e métodos}

Área de estudo - situa-se no Parque Estadual do Turvo, município de Derrubadas, noroeste do Rio Grande do Sul. O ponto central da parcela de 1 ha situa-se nas coordenadas $27^{\circ} 09^{\prime} \mathrm{S}$ e $53^{\circ} 53^{\prime} \mathrm{W}$, a 156 m.s.m., localizando-se em frente ao Salto do Yucumã. As formações florestais na região são classificadas como Floresta Estacional Decidual (Leite 2002), complementada para as áreas ribeirinhas segundo sugestões de Rodrigues (2001), como Floresta Estacional Decídua Ribeirinha. O clima é subtropical úmido, com precipitação pluviométrica média de $1.900 \mathrm{~mm}^{\circ}$ ano $^{-1}$ e temperatura média anual próxima a $19^{\circ} \mathrm{C}$ (SEMA 2005). O embasamento é basáltico, sendo típicos os Chernossolos Argilúvicos Férricos em associação com Neossolos Litólicos Eutróficos (SEMA 2005).

Levantamento de dados florísticos e estruturais - A coleta de dados estruturais foi realizada através do método de parcelas (Mueller-Dombois \& Ellenberg 1974), de $10 \times 10 \mathrm{~m}$, dispostas paralelamente ao curso do rio, em uma grade de $10 \times 10$ unidades amostrais (UAs), sem espaçamentos, totalizando 1 ha de floresta amostrada (Fig. 1). Todos os indivíduos arbóreos com perímetro à altura do peito (PAP) igual ou superior a $15 \mathrm{~cm}$ foram amostrados. Indivíduos apresentando ramificações do tronco abaixo de 1,3 $\mathrm{m}$ foram incluídos na amostra apenas em caso de no mínimo um dos perfilhos apresentar o PAP mínimo. A partir dos perímetros calculou-se a área basal que foi somada em caso de indivíduos com perfilhamentos. Indivíduos dispostos sobre os limites das UAs foram registrados nas parcelas que contiveram mais da metade de sua área basal. As identificações foram efetuadas ao nível de espécie, utilizando-se literatura especializada, consultas a herbários e envio a especialistas, quando necessário. O material testemunho coletado foi processado e incorporado ao acervo do Herbário ICN. Foi seguida para espécies a nomenclatura proposta por Sobral et al. (2006) e as famílias seguem a delimitação de APG II (2003).

Coleta de dados edáficos, topográficos e cobertura do dossel - Foram coletadas 12 amostras compostas por quatro sub-amostras de $500 \mathrm{~cm}^{3}$ de solo, cuja extração 


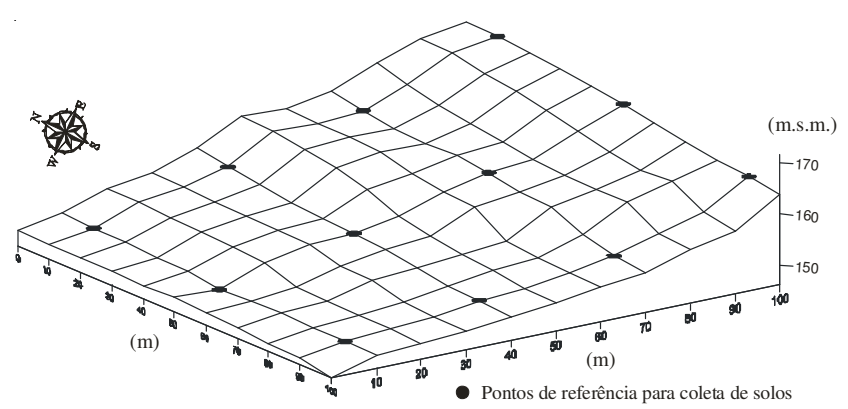

Figura 1. Aspecto da topografia, grade de unidades amostrais e pontos de referência para coleta de solos para análises químicas e físicas, de uma floresta ribeirinha do rio Uruguai, sul do Brasil.

foi alocada sistematicamente em blocos sem sobreposição, visando a abranger as principais variações na área demarcada (Fig. 1). Após a remoção da serapilheira, as amostras de solo foram coletadas na profundidade de 0-20 cm. As análises químicas e granulométricas foram realizadas conforme Tedesco et al. (1997). As variáveis químicas e físicas dos solos foram interpoladas pelo método de "kriging" para a aquisição de valores para o centro de cada UA (Hupy et al. 2005).

Determinou-se para as UAs a cota média de elevação sobre o nível do rio (Cota), obtida a partir da média das cotas estimadas nas extremidades de cada uma destas, e o desnível máximo (D), calculado através da diferença entre a maior e a menor cota encontrada em cada UA (Oliveira Filho et al. 1994). Para a medida das cotas foi utilizada uma mangueira plástica incolor contendo água e trenas métricas com graduação em centímetros (Cardoso \& Schiavini 2001).

Para avaliar a cobertura do dossel (CD) foram realizadas fotografias hemisféricas no centro de cada UA, a 1,6 m de altura. As fotografias foram processadas por meio do programa Gap Light Analyzer (Frazer et al. 1999), que após a conversão das imagens para branco e preto, contabiliza a proporção de "pixels" escuros, os quais são atribuídos a áreas com dossel cerrado.

A partir da variável Cota por UA e de dados provenientes do Sistema de Informações Hidrológicas, HidroWeb (ANA 2006), foi calculado o número de dias por ano que cada UA ficou inundada, em um período de 10 anos (janeiro/1994 a dezembro/2003). Para a utilização nas análises foi calculada a média anual de dias inundados para cada UA (dias ano $\left.{ }^{-1}\right)$.

Procedimento analítico - foram estimados primeiramente os parâmetros fitossociológicos: densidade, frequiência e dominância, em valores absolutos e relativos (MuellerDombois \& Ellenberg 1974); posteriormente, estes foram sumarizados pelo valor de importância (VI). Os cálculos foram realizados no programa FitopacShell 1.6 (Shepherd 2006). A diversidade foi avaliada pelo índice de Shannon
(H') e da equabilidade de Pielou (J'), calculados em base logarítmica neperiana (Brower \& Zar 1984).

As relações entre variáveis ambientais e a densidade das espécies nas UAs foram exploradas por meio de análise de correspondência canônica - CCA (ter Braak 1988), a qual possibilita extrair relações estreitas entre a matriz de abundância das espécies e das variáveis ambientais (Botrel et al. 2002; Oliveira Filho et al. 1997). Apenas espécies com no mínimo 10 indivíduos amostrados foram incluídas na análise, resultando na matriz de espécies - ME. Todas variáveis ambientais medidas em porcentagem receberam transformação escalar: $b=(2 / \pi)$. $\operatorname{arco} \operatorname{seno}\left(\sqrt{ }_{\mathrm{ij}}+1\right)$. As variáveis ambientais foram avaliadas quanto à relação com a ME em um procedimento passo a passo, por meio de testes de permutação de Monte Carlo (10.000 iterações, $\alpha=0,05$; Manly 1991), e removidas em caso de não apresentarem associação significativa. A CCA foi executada com o auxílio do programa Canoco 4.5 (ter Braak \& Šmilauer 2002). Os efeitos da autocorrelação espacial foram extraídos pelo método de CCA "parcial" descrito por Borcard et al. (1992) e detalhado por Titeux et al. (2004). Para isso foi utilizada uma matriz adicional com as coordenadas métricas $x$ e $y$ do centro de cada UA (além do termo $x y$ ), visando a avaliação de padrões de distribuição lineares (Borcard et al. 1992) e os termos do polinômio de segunda e terceira ordem resultante $\left(x^{2}\right.$, $y^{2}, x^{2} y, x y^{2}, x^{3}$ e $\left.y^{3}\right)$, visando detectar distribuições unimodais ou enviesadas ou, ainda, combinações destas (Guisan \& Zimmermann 2000).

As UAs foram classificadas por meio de análise de agrupamento não hierárquica de $k$-médias ("k-means clustering") em que $k$ é o número de grupos especificado e cujo algoritmo é similar ao da variância mínima (método de Ward). Esse método não força o aninhamento durante a formação dos grupos, o que possibilita avaliar a hierarquia a posteriori (Dufrêne \& Legendre 1997). Os dados utilizados foram as variáveis com maiores correlações com o primeiro eixo da CCA, pois estas devem determinar os principais gradientes florísticos e, desta forma, padrões estruturais. Nos grupos resultantes, as medianas por UAs dos principais parâmetros estruturais e dos índices de diversidade foram avaliadas por análise de variância em postos de Kruskal-Wallis (dados não-normalizados), $\operatorname{com} \alpha=0,05$. Em caso de diferenças significativas, os grupos foram comparados par-apar pelo método de Dunn, devido ao diferente número de amostras em cada grupo (Brower \& Zar 1984).

\section{Resultados e discussão}

Ambiente abiótico - As variáveis ambientais analisadas, suas médias, desvios padrões e relações numéricas com 
a matriz de espécies são apresentados na Tab. 1. A diferença nas cotas de elevação totalizou $24,7 \mathrm{~m}$, com desníveis leves nas áreas mais próximas à margem do rio, e moderados a altos nas unidades amostrais centrais e opostas ao rio, respectivamente. $\mathrm{O} \mathrm{pH}$ das amostras variou de 5,2 a 6,3 , ficando compreendidos nas classificações "pH baixo", "pH médio" e "pH alto" para o Rio Grande do Sul (Tomé Jr. 1997). Nas áreas de pH baixo ocorreram valores altos de $\mathrm{Al}$ trocável e $\mathrm{Mn}$, indicando possível toxidez por estes elementos. De acordo com Sollins (1998), os efeitos deletérios do Al ocorrem diretamente sobre o crescimento e função das raízes. Estes trechos possuem menores valores de $\mathrm{Ca}$, $\mathrm{Mg}$ e K, macronutrientes importantes na determinação da fertilidade dos solos (Tomé Jr. 1997). Em relação ao $\mathrm{pH}$, van Schaik \& Mirmanto (1985) encontraram correlação negativa deste parâmetro com a estatura e o tempo de vida de espécies arbóreas na ilha de Sumatra, embora sejam necessários mais estudos neste sentido (Sollins 1998).

A quantidade de matéria orgânica (M.O.) e partículas granulométricas finas e médias (argila e silte) apresentaram maiores valores nas áreas mais elevadas, possivelmente condicionadas pela remoção da serapilheira pelas inundações (Rodrigues \& Shepherd 2001), freqüentes próximo ao leito. As baixas quantidades de M.O. nas partes baixas indicam também que os solos são muito bem drenados, pois o encharcamento reduz a mineralização desta (Tomé Jr. 1997). Os valores mensurados para os nutrientes $\mathrm{B}, \mathrm{S}$ e $\mathrm{P}$ aumentaram simultaneamente com M.O., pois a decomposição da vegetação é geralmente a maior fonte destes compostos (Tomé Jr. 1997). As inundações podem ainda causar alterações na granulometria dos solos por erosão das partículas menores (Johnson et al. 1985; Ritchie et al. 2005) ou compactação, reduzindo a quantidade de poros e, assim, a disponibilidade de $\mathrm{O}_{2}$ (Blom \& Voesenek 1996). Para a área, a predominância de partículas grossas nas amostras das áreas próximas ao rio denota erosão de partículas no solo superficial $(0-20 \mathrm{~cm})$, embora isso não seja evidência de que a compactação não ocorra nas partes mais profundas. O transporte de sedimentos resulta em sedimentação ou erosão e trata-se de um processo que ocorre na escala espacial local e temporal de décadas (Richards et al. 2002), sendo, portanto, capaz de gerar e alterar os padrões de heterogeneidade do ambiente físico.

A soma de bases (V) foi superior a $50 \%$ em todas amostras, caracterizando os solos como eutróficos em relação a esta variável. Um pequeno trecho, correspondente a uma amostra de solo (e as quatro UAs correspondentes), foi classificado como álico-distrófico, devido à presença de quantidades elevadas de $\mathrm{Al}$ trocável (Tomé Jr. 1997). Exceto neste trecho, a área apresentou solos férteis, apesar das estimativas de fertilidade terem sido baseadas em respostas de plantas cultivadas.

Tabela 1. Médias e desvio padrão das variáveis ambientais mensuradas e sua relação com a matriz de espécies em uma parcela de 1 ha de uma floresta ribeirinha do rio Uruguai, sul do Brasil. V: variação da matriz de espécies explicada pela variável independentemente; VC: variação cumulativa da matriz de espécies explicada pela variável e aquelas anteriormente incluídas na ordenação. F e $P$ resultantes de teste de permutação de Monte Carlo. Método e/ou unidades de medida das variáveis entre colchetes.

\begin{tabular}{|c|c|c|c|c|c|}
\hline Variável & Média \pm DP & $\mathrm{V}(\%)$ & $\mathrm{VC}(\%)$ & $\mathrm{F}$ & $P$ \\
\hline Inundação média (dias ano-1) & $12,06 \pm 18,30$ & 15,25 & 15,25 & 17,452 & 0,001 \\
\hline Cota média de elevação - Cota (m) & $156,85 \pm 6,31$ & 13,40 & 22,35 & 8,789 & 0,001 \\
\hline Matéria orgânica - M.O. (\%) & $3,42 \pm 2,21$ & 12,79 & 24,03 & 2,096 & 0,002 \\
\hline $\mathrm{P}\left(\operatorname{Mehlich}\left(\mathrm{mg} \mathrm{dm}^{-3}\right)\right)$ & $6,23 \pm 3,07$ & 1,70 & 25,78 & 2,228 & 0,001 \\
\hline Acidez potencial $-\mathrm{Al}+\mathrm{H}\left(\mathrm{cmolc}_{\mathrm{dm}}^{-3}\right)$ & $2,25 \pm 0,80$ & 3,11 & 27,02 & 1,571 & 0,025 \\
\hline $\mathrm{pH}\left(\mathrm{em} \mathrm{H}_{2} \mathrm{O} 1: 1\right)^{*}$ & $5,78 \pm 0,32$ & 5,96 & 30,20 & 4,195 & 0,001 \\
\hline Partículas grossas (Areia) - PG (\%)* & $49,58 \pm 28,94$ & 3,87 & 34,78 & 2,963 & 0,001 \\
\hline $\mathrm{Zn}\left(\mathrm{mg} \mathrm{dm}^{-3}\right)^{*}$ & $9,25 \pm 4,28$ & 15,35 & 32,56 & 3,268 & 0,001 \\
\hline Soma de bases $-\mathrm{V}(\%)^{*}$ & $87,42 \pm 5,16$ & 3,16 & 36,60 & 2,549 & 0,001 \\
\hline $\operatorname{Mn}\left(\mathrm{mg} \mathrm{dm}^{-3}\right)^{*}$ & $4,25 \pm 4,92$ & 5,25 & 38,40 & 2,565 & 0,001 \\
\hline Capacidade de Troca Catiônica - CTC $\left(\mathrm{cmolc} \mathrm{dm}^{-3}\right)^{*}$ & $19,13 \pm 6,58$ & 6,52 & 39,62 & 1,735 & 0,008 \\
\hline $\left.\mathrm{B}(\mathrm{mg} \mathrm{dm})^{-3}\right)^{*}$ & $0,48 \pm 0,07$ & 6,86 & 40,64 & 1,465 & 0,035 \\
\hline $\mathrm{S}\left(\mathrm{mg} \mathrm{dm}^{-3}\right)^{*}$ & $6,82 \pm 0,74$ & 7,44 & 41,68 & 1,506 & 0,035 \\
\hline Desnível - D (m)* & $2,52 \pm 1,80$ & 7,03 & 42,61 & 1,352 & 0,078 \\
\hline Cobertura do dossel - CD $(\%)^{*}$ & $86 \pm 0,04$ & 6,71 & 43,36 & 1,093 & 0,362 \\
\hline Partículas finas e médias (Argila e Silte) - PFM (\%)** & $50,42 \pm 28,94$ & - & - & - & - \\
\hline $\mathrm{Ca}\left(\mathrm{cmolc} \mathrm{dm}^{-3}\right) * * *$ & $12,15 \pm 5,39$ & - & - & - & - \\
\hline $\operatorname{Mg}\left(\mathrm{cmolc} \mathrm{dm}^{-3}\right)^{* * *}$ & $4,48 \pm 1,34$ & - & - & - & - \\
\hline $\left.\mathrm{K}(\mathrm{mg} \mathrm{dm})^{-3}\right) * * *$ & $105,50 \pm 59,36$ & - & - & - & - \\
\hline $\mathrm{Cu}\left(\mathrm{mg} \mathrm{dm}^{-3}\right) * * * *$ & $5,90 \pm 4,48$ & - & - & - & - \\
\hline
\end{tabular}

*Redundância com Cota; **Colinearidade com PG; ***Colinearidade com CTC; ****Colinearidade com PG, V, Zn e Mn. 
Caracteristicamente, existe na área um aumento progressivo da Capacidade de Troca Catiônica (CTC) com o afastamento do rio. A CTC moderada a alta contrasta com o trabalho de Budke et al. (2007), que encontraram solos eutróficos e distróficos alternando-se em curtas distâncias devido a variações microtopográficas. Esse tipo de diferença pode ser atribuído a diferenças geomorfológicas de diferentes setores da bacia hidrográfica (Tabacchi et al. 1998). Segundo esta delimitação, o setor do rio Botucaraí, estudado por Budke et al. (2007), possui características de área de deposição de sedimentos (setor deposicional), enquanto na área do presente estudo, a deposição é rara, sendo mais comum a erosão (setor erosional).

A variável cobertura do dossel (CD) apresentou-se bastante uniforme em grande parte da área, embora nas parcelas adjacentes ao rio, bem como em uma clareira dominada pela espécie apoiante Celtis iguanaea (Jacq.) Sarg. (Cannabaceae), a variável tenha apresentado valores menores. Se utilizado o critério de Suzuki et al. (2002) para a definição de clareira, que é a ausência de dossel a partir de $10 \mathrm{~m}$, todas as UAs localizadas até $20 \mathrm{~m}$ do leito do rio se enquadram nesta condição, pois não apresentaram nenhum indivíduo com $10 \mathrm{~m}$ ou mais de altura. Contudo, a estrutura diferenciada, relacionada com uma composição florística particular determinada por outras variáveis ambientais nas áreas adjacentes ao rio, foram entendidas como geradoras de menor cobertura, não sendo a maior disponibilidade de luz um fator seletivo de espécies no estádio adulto, evidenciado pela baixa relação da variável CD com a matriz de espécies.

Vegetação e estrutura - Foram encontradas 82 espécies distribuídas em 66 gêneros e 30 famílias (Tab. 2). Destacaram-se as famílias Fabaceae (com 16 espécies), seguida por Myrtaceae (15), Euphorbiaceae (seis), Meliaceae, Rutaceae (cino) e Sapindaceae (quatro), totalizando $62,6 \%$ das espécies. Os gêneros com maior número de espécies foram Eugenia L. (sete espécies), Sebastiania Spreng. e Trichilia P. Browne (três). Das espécies amostradas, $31,1 \%$ estão incluídas na lista daquelas que ocorrem com maior freqüência em florestas ribeirinhas do Brasil extra-amazônico (Rodrigues \& Nave 2001).

A elevada riqueza específica de Fabaceae e Myrtaceae no local deve resultar, em parte, da ampla representatividade destas famílias nas formações florestais do Rio Grande do Sul. Fabaceae se destaca pela quantidade de espécies que alcançam o Estado pela rota de migração das bacias dos rios Paraná e Uruguai (Rambo 1961). Muitas espécies da família também são citadas como estruturalmente importantes nas florestas estacionais da Região Sul, com a presença de determinadas espécies constituindo critério nomenclatural, principalmente naquelas derivadas das classificações do RADAMBASIL (e.g., Leite 2002). Nessas, a abundância de espécies emergentes caducifólias da família costuma atribuir a denominação de Floresta Estacional 'Decídua' às tipologias. Por outro lado, a família Myrtaceae apresenta o maior número de espécies arbóreas no Estado, se destacando também pela participação na composição florística de todas as formações florestais (Reitz et al. 1983, Sobral et al. 2006). Estes dados aliam-se a constatação progressivamente ratificada da importância de ambos táxons em formações ribeirinhas no sul do Brasil. A mesma ordem foi encontrada na compilação de Rodrigues \& Nave (2001), sendo Fabaceae a família com maior riqueza (125 espécies; $13,2 \%$ do total), seguida por Myrtaceae (106; 11,2\%). Por outro lado, quase dois terços das famílias apresentaram apenas uma espécie $(63,3 \%)$, valor semelhante ao encontrado no ribeirão dos Apertados, próximo à Londrina, Paraná (61\%; Bianchini et al. 2003).

A diversidade específica $H^{\prime}$ resultou em 3,680 e o índice J' em 0,833 . Os valores são superiores a outras florestas ribeirinhas no Rio Grande do Sul (exs. H' = 2,73 e J' = 0,69 em Budke et al. 2004; H' = 1,995 e J' = 0,586 em Budke et al. 2007, na mesma base logarítmica do presente estudo), o que pode ser atribuído à contribuição de espécies típicas de áreas de interflúvio nas áreas mais altas, e substituição de espécies com o afastamento do rio, não permitindo dominâncias elevadas. A baixa dominância ecológica pode ser avaliada pelos baixos valores de importância acumulados, sempre inferiores a $10 \%$.

A densidade total foi de 1.617 ind. ha ${ }^{-1} \mathrm{e}$ a área basal, $26,32 \mathrm{~m}^{2}$. Quinze espécies apresentaram apenas um indivíduo e seis espécies dois indivíduos. As espécies com maior VI foram Sorocea bonplandii, Guarea macrophylla, Inga marginata e Sebastiania commersoniana, somando $21,7 \%$ do total para o parâmetro. As 10 espécies com maior VI somaram 41,7\% do total deste, enquanto as 15 espécies com apenas um indivíduo amostrado acumularam apenas ca. 1,3\% do mesmo. Vários levantamentos em formações florestais no estado apresentam o mesmo padrão, com espécies de sub-bosque com valores destacados de VI, o que é resultante de altas densidades e/ou freqüências. O padrão resultante da avaliação das densidades coincidiu com o VI para as primeiras espécies, embora as maiores freqüências reportadas tenham sido médias (56\% para S. bonplandii e $53 \%$ para G. macrophylla, correspondendo pouco mais da metade da área de estudo). Os valores encontrados podem ser considerados baixos em relação a outros estudos na região. Por exemplo, Budke et al. (2004) encontraram em uma floresta ribeirinha, respectivamente, 82 e $81 \%$ de freqüência, além de densidades elevadas para Eugenia uniflora L. e 
Tabela 2. Espécies, respectivas famílias botânicas, densidades (D), freqüências (F), áreas basais (AB em m²) e valores de importância (VI) correspondentes à amostragem do componente arbóreo em floresta ribeirinha do rio Uruguai, sul do Brasil. *Espécie alóctone no local.

\begin{tabular}{|c|c|c|c|c|}
\hline Família/Espécie & $\mathrm{D}$ & $\mathrm{F}$ & $\mathrm{AB}$ & VI \\
\hline \multicolumn{5}{|l|}{ ACHATOCARPACEAE } \\
\hline Achatocarpus praecox Griseb. & 3 & 2 & 0,022 & 0,159 \\
\hline \multicolumn{5}{|l|}{ ANNONACEAE } \\
\hline Rollinia salicifolia (A.St.-Hil.) Mart. & 4 & 4 & 0,051 & 0,284 \\
\hline \multicolumn{5}{|l|}{ APOCYNACEAE } \\
\hline Tabernaemontana catharinensis DC. & 1 & 1 & 0,034 & 0,097 \\
\hline \multicolumn{5}{|l|}{ ARECACEAE } \\
\hline Syagrus romanzoffiana (Cham.) Glassman & 8 & 8 & 0,106 & 0,574 \\
\hline \multicolumn{5}{|l|}{ BORAGINACEAE } \\
\hline Cordia ecalyculata Vell. & 3 & 2 & 0,021 & 0,158 \\
\hline \multicolumn{5}{|l|}{ CANNABACEAE } \\
\hline Trema micrantha (L.) Blume & 1 & 1 & 0,007 & 0,063 \\
\hline \multicolumn{5}{|l|}{ CARICACEAE } \\
\hline Jacaratia spinosa (Aubl.) DC. & 4 & 3 & 0,200 & 0,439 \\
\hline \multicolumn{5}{|l|}{ COMBRETACEAE } \\
\hline Terminalia australis Cambess. & 37 & 13 & 0,529 & 1,878 \\
\hline \multicolumn{5}{|l|}{ ERYTHROXYLACEAE } \\
\hline Erythroxylum cuneifolium (Mart.) O.E.Schulz & 1 & 1 & 0,003 & 0,059 \\
\hline \multicolumn{5}{|l|}{ EUPHORBIACEAE } \\
\hline Alchornea triplinervia (Spreng.) Müll.Arg. & 12 & 11 & 1,659 & 2,726 \\
\hline Gymnanthes concolor Spreng. & 68 & 33 & 0,189 & 2,772 \\
\hline Sebastiania brasiliensis Spreng. & 59 & 33 & 0,457 & 2,926 \\
\hline S. commersoniana (Baill.) L.B.Sm. \& Downs & 76 & 44 & 0,924 & 4,244 \\
\hline S. schottiana (Müll.Arg.) Müll. Arg. & 23 & 8 & 0,143 & 0,929 \\
\hline Tetrorchidium rubrivenium Poepp. \& Endl. & 1 & 1 & 0,024 & 0,085 \\
\hline \multicolumn{5}{|l|}{ FABACEAE } \\
\hline Apuleia leiocarpa (Vogel) Macbr. & 11 & 11 & 2,756 & 4,095 \\
\hline Ateleia glazioviana Baill. & 8 & 6 & 0,270 & 0,713 \\
\hline Calliandra foliolosa Benth. & 4 & 3 & 0,017 & 0,207 \\
\hline Dahlstedtia pinnata (Benth.) Malme & 10 & 9 & 0,034 & 0,557 \\
\hline Enterolobium contortisiliquum (Vell.) Morong & 1 & 1 & 0,208 & 0,318 \\
\hline Erythrina falcata Benth. & 2 & 1 & 0,121 & 0,228 \\
\hline Holocalyx balansae Mich. & 7 & 6 & 0,352 & 0,796 \\
\hline Inga marginata Willd. & 108 & 47 & 0,867 & 4,935 \\
\hline I. vera Willd. & 65 & 26 & 0,634 & 3,034 \\
\hline Lonchocarpus campestris Benth. & 17 & 15 & 0,396 & 1,366 \\
\hline Machaerium hirtum (Vell.) Stellfeld & 8 & 6 & 0,338 & 0,798 \\
\hline M. stipitatum (DC.) Vogel & 9 & 12 & 0,345 & 1,034 \\
\hline Mimosa bimucronata (DC.) O.Kuntze & 2 & 2 & 0,021 & 0,136 \\
\hline \multicolumn{5}{|l|}{ FABACEAE } \\
\hline Parapiptadenia rigida (Benth.) Brenan & 13 & 9 & 0,355 & 1,026 \\
\hline Peltophorum dubium (Spreng.) Taub. & 4 & 4 & 0,182 & 0,450 \\
\hline Poecilanthe parviflora Benth. & 12 & 7 & 0,340 & 0,917 \\
\hline \multicolumn{5}{|l|}{ LAMIACEAE } \\
\hline Vitex megapotamica (Spreng.) Moldenke & 8 & 6 & 1,412 & 2,158 \\
\hline \multicolumn{5}{|l|}{ LAURACEAE } \\
\hline Nectandra megapotamica (Spreng.) Mez & 24 & 19 & 1,035 & 2,456 \\
\hline Ocotea puberula (Rich.) Nees & 1 & 1 & 0,002 & 0,057 \\
\hline \multicolumn{5}{|l|}{ MALVACEAE } \\
\hline Luehea divaricata Mart. \& Zucc. & 28 & 23 & 1,875 & 3,741 \\
\hline \multicolumn{5}{|l|}{ MELASTOMATACEAE } \\
\hline Miconia pusilliflora (DC.) Naudin & 5 & 5 & 0,016 & 0,295 \\
\hline \multicolumn{5}{|l|}{ MELIACEAE } \\
\hline Cabralea canjerana (Vell.) Mart. & 4 & 4 & 0,036 & 0,265 \\
\hline Guarea macrophylla Vahl & 112 & 53 & 1,257 & 5,717 \\
\hline Trichilia catigua A.Juss. & 58 & 38 & 0,273 & 2,843 \\
\hline T. clausseni C.DC. & 46 & 28 & 0,441 & 2,466 \\
\hline T. elegans A.Juss. & 1 & 1 & 0,003 & 0,058 \\
\hline
\end{tabular}


Tabela 2 (continuação)

\begin{tabular}{|c|c|c|c|c|}
\hline Família/Espécie & $\mathrm{D}$ & $\mathrm{F}$ & $\mathrm{AB}$ & VI \\
\hline \multicolumn{5}{|l|}{ MORACEAE } \\
\hline Ficus citrifolia Mill. & 10 & 10 & 0,188 & 0,787 \\
\hline Maclura tinctoria (L.) D. Don. & 5 & 5 & 0,244 & 0,583 \\
\hline Sorocea bonplandii (Baill.) W.C. Burger et al. & 182 & 56 & 0,892 & 6,800 \\
\hline \multicolumn{5}{|l|}{ MYRSINACEAE } \\
\hline Myrsine loefgrenii (Mez) Imkhan. & 17 & 15 & 0,047 & 0,924 \\
\hline \multicolumn{5}{|l|}{ MYRTACEAE } \\
\hline Blepharocalyx salicifolius (Kunth) O. Berg & 21 & 13 & 0,357 & 1,331 \\
\hline Calyptranthes concinna DC. & 33 & 14 & 0,139 & 1,336 \\
\hline C. tricona D.Legrand & 7 & 7 & 0,083 & 0,489 \\
\hline Campomanesia guazumifolia (Cambess.) O. Berg & 3 & 3 & 0,034 & 0,208 \\
\hline Campomanesia xanthocarpa O. Berg & 2 & 2 & 0,205 & 0,369 \\
\hline Eugenia florida DC. & 21 & 18 & 0,504 & 1,688 \\
\hline E. hiemalis Cambess. & 14 & 13 & 0,083 & 0,839 \\
\hline E. involucrata DC. & 1 & 1 & 0,005 & 0,061 \\
\hline E. pluriflora DC. & 2 & 2 & 0,005 & 0,116 \\
\hline E. subterminalis DC. & 31 & 20 & 0,399 & 1,830 \\
\hline E. pyriformis Cambess. & 1 & 1 & 0,010 & 0,068 \\
\hline Eugenia uruguayensis Cambess. & 34 & 19 & 0,218 & 1,628 \\
\hline Myrceugenia glaucescens (Cambess.) D. Legrand \& Kausel & 30 & 20 & 0,296 & 1,678 \\
\hline Myrciaria tenella (DC.) O. Berg & 17 & 9 & 0,053 & 0,726 \\
\hline \multicolumn{5}{|l|}{ MYRTACEAE } \\
\hline Plinia rivularis (Cambess.) Rotman & 13 & 11 & 0,228 & 0,933 \\
\hline \multicolumn{5}{|l|}{ POLYGONACEAE } \\
\hline Ruprechtia laxiflora Meisn. & 1 & 1 & 0,002 & 0,057 \\
\hline \multicolumn{5}{|l|}{ PROTEACEAE } \\
\hline Roupala brasiliensis Klotzsch & 4 & 3 & 0,011 & 0,200 \\
\hline \multicolumn{5}{|l|}{ ROSACEAE } \\
\hline Prunus myrtifolia (L.) Urb. & 4 & 4 & 0,068 & 0,306 \\
\hline \multicolumn{5}{|l|}{ RUBIACEAE } \\
\hline Chomelia obtusa Cham. \& Schltdl. & 51 & 26 & 0,312 & 2,337 \\
\hline Guettarda uruguensis Cham. \& Schltdl. & 11 & 8 & 0,067 & 0,585 \\
\hline \multicolumn{5}{|l|}{ RUTACEAE } \\
\hline Balfourodendron riedelianum (Engl.) Engl. & 1 & 1 & 0,010 & 0,068 \\
\hline Citrus reticulata Blanco* & 1 & 1 & 0,009 & 0,066 \\
\hline C. sinensis $(\mathrm{L}$.$) Osbeck*$ & 16 & 12 & 0,093 & 0,858 \\
\hline Pilocarpus pennatifolius Lam. & 1 & 1 & 0,003 & 0,058 \\
\hline Zanthoxylum petiolare A.St.-Hil. \& Tul. & 1 & 1 & 0,006 & 0,063 \\
\hline \multicolumn{5}{|l|}{ SALICACEAE } \\
\hline Banara tomentosa Clos & 4 & 4 & 0,064 & 0,300 \\
\hline Casearia sylvestris $\mathrm{Sw}$. & 23 & 20 & 0,171 & 1,376 \\
\hline \multicolumn{5}{|l|}{ SAPINDACEAE } \\
\hline Allophylus edulis (A.St.-Hil. et al.) Radlk. & 12 & 12 & 0,082 & 0,762 \\
\hline Cupania vernalis Cambess. & 5 & 5 & 0,043 & 0,329 \\
\hline Diatenopteryx sorbifolia Radlk. & 15 & 15 & 0,918 & 1,986 \\
\hline Matayba elaeagnoides Radlk. & 58 & 32 & 0,741 & 3,231 \\
\hline \multicolumn{5}{|l|}{ SAPOTACEAE } \\
\hline Chrysophyllum gonocarpum (Mart. \& Eichler) Engl. & 23 & 22 & 0,280 & 1,582 \\
\hline C. marginatum (Hook. \& Arn.) Radlk. & 42 & 35 & 0,734 & 2,994 \\
\hline Pouteria salicifolia (Spreng.) Radlk. & 20 & 12 & 0,636 & 1,629 \\
\hline \multicolumn{5}{|l|}{ STYRACACEAE } \\
\hline Styrax leprosus Hook. \& Arn. & 3 & 3 & 0,030 & 0,203 \\
\hline \multicolumn{5}{|l|}{ THYMELAEACEAE } \\
\hline Daphnopsis racemosa Griseb. & 1 & 1 & 0,002 & 0,057 \\
\hline \multicolumn{5}{|l|}{ URTICACEAE } \\
\hline Urera baccifera (L.) Gaudich. & 5 & 5 & 0,060 & 0,350 \\
\hline
\end{tabular}


Gymnanthes concolor. Em um levantamento realizado em floresta de encosta, Jarenkow \& Waechter (2001) encontraram $99 \%$ de freqüência para G. concolor, e $88 \%$ para Euterpe edulis Mart. e S. bonplandii, que também apresentaram densidades elevadas.

No presente estudo a ausência de um dossel florestal típico a partir de $10 \mathrm{~m}$, pode ser considerada como fator limitante ao estabelecimento de $S$. bonplandii, pois a mesma é típica de sub-bosque. Já G. macrophylla foi abundante nas áreas sem dossel. Espécies do gênero Inga Mill. são típicas de florestas ribeirinhas (Bertani et al. 2001; Damasceno-Junior et al. 2005), embora I. marginata tenha apresentado maior freqüência nos trechos mais elevados, enquanto Inga vera (oitavo VI) esteja associada às áreas baixas, próximas ao rio. $\mathrm{O}$ alto VI de $S$. commersoniana já foi reportado em outras florestas ribeirinhas de vários locais do Brasil (Botrel et al. 2002; Budke et al. 2004; 2007), sendo sua anatomia adaptada a ambientes inundáveis (Kolb et al. 1998).

Ordenação de espécies - O primeiro eixo canônico de ordenação foi significativo (autovalor $=0,665$; $\mathrm{F}=17,928 ; P<0,001)$, assim como a totalidade de eixos canônicos (soma dos autovalores $=1,111 ; \mathrm{F}=6,886$; $P<0,001)$. A soma dos autovalores canônicos corresponde a $27 \%$ do total (variação da ME explicada pelas variáveis ambientais mantidas na análise). A separação das espécies no diagrama de ordenação denota um padrão nítido nos escores das espécies (Fig. 2), resultado da substituição progressiva no ambiente em função da elevação das cotas de elevação. A disposição seqüencial das espécies indica aquelas de áreas suscetíveis a inundações à direita do diagrama, e aquelas de interflúvio à esquerda. O efeito arco resultante foi interpretado como evidência de um gradiente vegetacional apenas, com associação muito elevada com o primeiro eixo de variáveis ambientais, devendo ser atribuída maior atenção à disposição horizontal dos escores das espécies, já que a disposição vertical trata de um gradiente pouco definido, ou mesmo, apenas um artefato. $\mathrm{O}$ primeiro eixo de ordenação das espécies correlacionou-se fortemente com as variáveis 'Inundações', 'Cota' e 'M.O.', enquanto o segundo apresentou uma relação adicional com a acidez potencial e com os teores de fósforo. As demais variáveis foram excluídas após análise dos fatores de inflação e constatação de que grande parte da informação adicionada com sua inclusão era redundante. 'Inundações' e 'M.O.' também apresentam certa redundância com 'Cota', mas foram mantidas, pois se considerou que estas possuem fontes de variação diferenciadas e, portanto, seus resíduos poderiam acrescentar informações.

Vários autores já encontraram relações entre a vegetação e conjuntos semelhantes de variáveis ambientais em florestas ribeirinhas. Grande parte dos
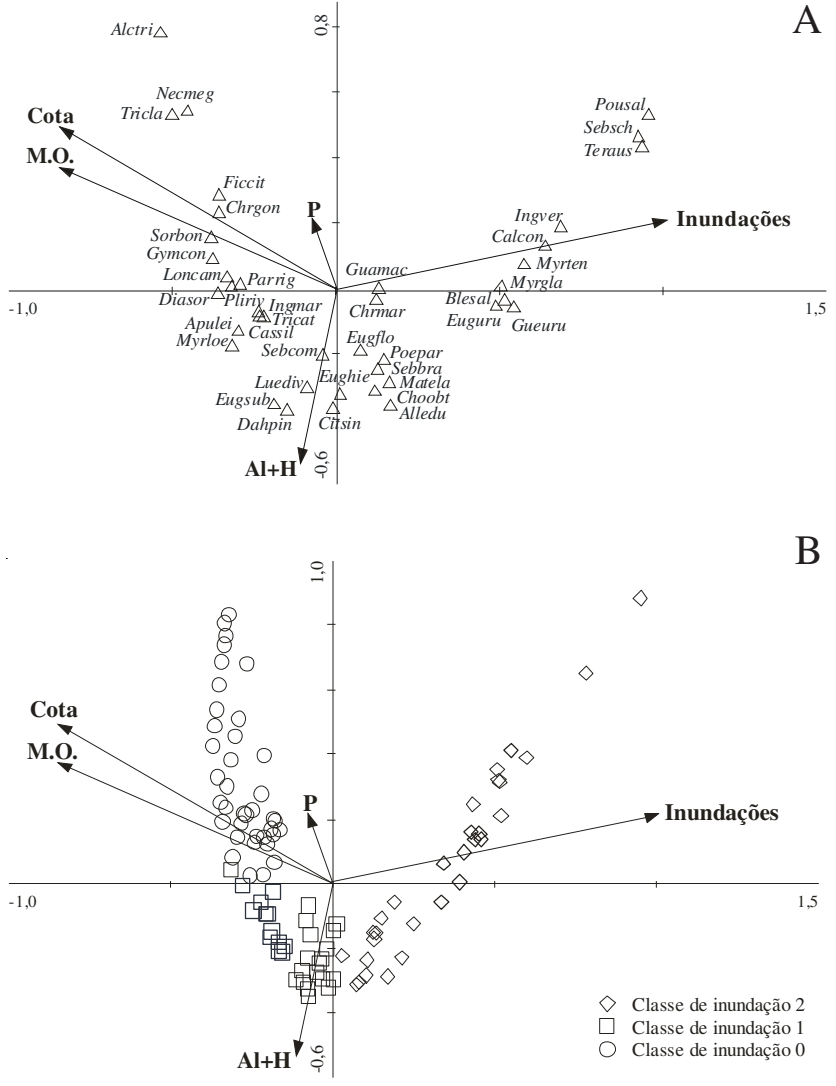

Figura 2. A. Diagrama de ordenação para espécies com mais de 10 indivíduos e variáveis ambientais com associação significativa e B. Para unidades amostrais e variáveis ambientais, representando os dois primeiros eixos gerados por análise de correspondência canônica (CCA), de uma floresta ribeirinha do rio Uruguai, sul do Brasil. Os nomes das variáveis ambientais e das espécies (três letras do gênero + três letras do epíteto específico) foram abreviados e os nomes completos estão na Tab. 1 e Tab. 2 , respectivamente. As classes de inundação foram calculadas por análise de agrupamento, sendo freqüentes na classe 2, eventuais na classe 1 e raras na classe 0 .

trabalhos demonstrou relações das espécies com variáveis físicas e químicas. Alguns assinalam relações com diferentes cotas de elevação (Oliveira Filho et al. 1994; van den Berg \& Oliveira-Filho 1999; Cardoso \& Schiavini 2002; Damasceno Junior et al. 2005; Budke et al. 2007), umidade do solo (van den Berg \& Oliveira Filho 1999; Cardoso \& Schiavini 2002), inundações (Rosales et al. 2001; Damasceno Junior et al. 2005; Budke et al. 2007), classes de drenagem (Botrel et al. 2002) e partículas granulométricas (Rosales et al. 2001; Botrel et al. 2002), profundidade do lençol freático e arranjo dos poros do solo (Sollins 1998), erosão e extensão da elevação (Oliveira Filho et al. 1994). Em relação às variáveis químicas, Sollins (1998) relatou a disponibilidade de P, a toxicidade por $\mathrm{Al}$ e a disponibilidade de cátions $\mathrm{e}$ micronutrientes e $\mathrm{N}$, como fatores de maior influência na vegetação tropical de terras baixas. Não raro são encontradas diferenças na fertilidade ao longo de áreas ribeirinhas, onde a resposta positiva da vegetação é 
assinalada pela relação com a saturação por bases $(\mathrm{V})$ (Botrel et al. 2002; Budke et al. 2007), disponibilidade de P (Oliveira Filho et al. 1994; Rosales et al. 2001), disponibilidade de matéria orgânica (Rosales et al. 2001) e coeficiente de troca catiônica (Oliveira Filho et al. 1994). Apesar de uma aparente dicotomia e de um maior número de trabalhos citando variáveis físicas como sendo aquelas de maior influência sobre a vegetação, no presente estudo a alta correlação entre os conjuntos físico e químico sugere interdependência. As relações avaliadas por regressão linear entre algumas variáveis mensuradas são mostradas na Fig. 3. A granulometria dos solos e os teores de M.O., como abordado anteriormente, podem ser alterados pelas inundações, que são mais freqüentes nas áreas de menor elevação, disso derivando as correlações positivas para 'Cota'- 'M.O.' e negativas para 'Cota'-'Areia'. O carreamento da serapilheira acaba por ocasionar a perda local de inúmeros nutrientes, utilizados na estimativa da CTC. Desta forma, é adequado tratar as variáveis ambientais como interdependentes e hierarquizadas, com a cota de elevação determinando a dinâmica de outras condições abióticas.
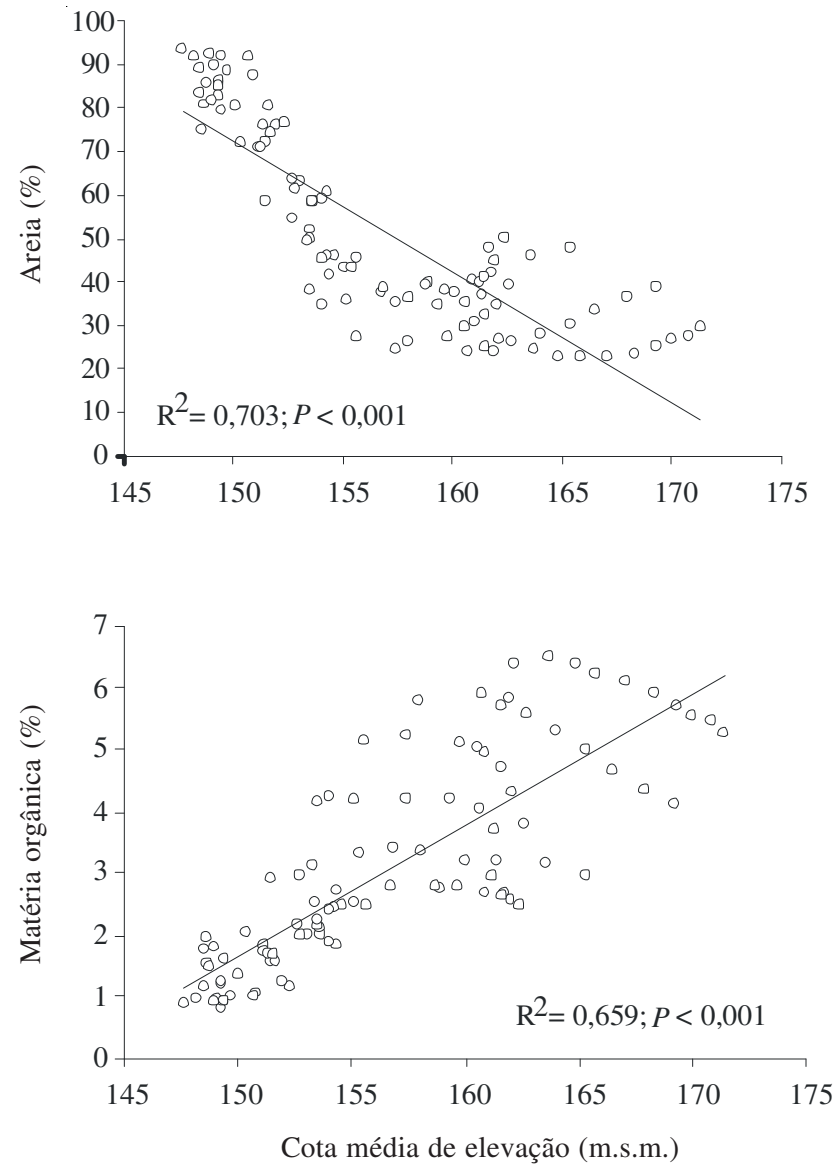

Para a CCA "parcial" procedeu-se inicialmente a avaliação das variáveis espaciais quanto à relação com a matriz das espécies. A análise dos fatores de inflação e das correlações resultou na manutenção dos termos $x \mathrm{e}$ $y$ apenas, denotando estrutura espacial predominantemente linear. A variável $y$, que mede a distância das UAs até o rio, apresentou correlação elevada com o primeiro eixo de ordenação das espécies, quando desconsideradas as variáveis ambientais $(r=0,923)$. Cerca de $30 \%$ da variação na matriz de espécies pode ser explicada pelas variáveis ambientais, estrutura espacial e autocorrelação espacial (Fig. 4). As frações I e II resultam da divisão da variação explicada pela CCA "não parcial" (Fig. 2). Assim, a fração I corresponde à variação da matriz de espécies atribuível às variáveis ambientais incluídas no modelo; já a fração II corresponde a uma sobreposição entre a estrutura espacial das variáveis ambientais e das espécies que não é estritamente previsível, podendo resultar da interação destas, ou ainda se tratar de uma resposta comum a variáveis não mensuradas (Borcard et al. 2002). A fração III representa a $\mathrm{AE}$ das espécies que não é compartilhada pelas variáveis
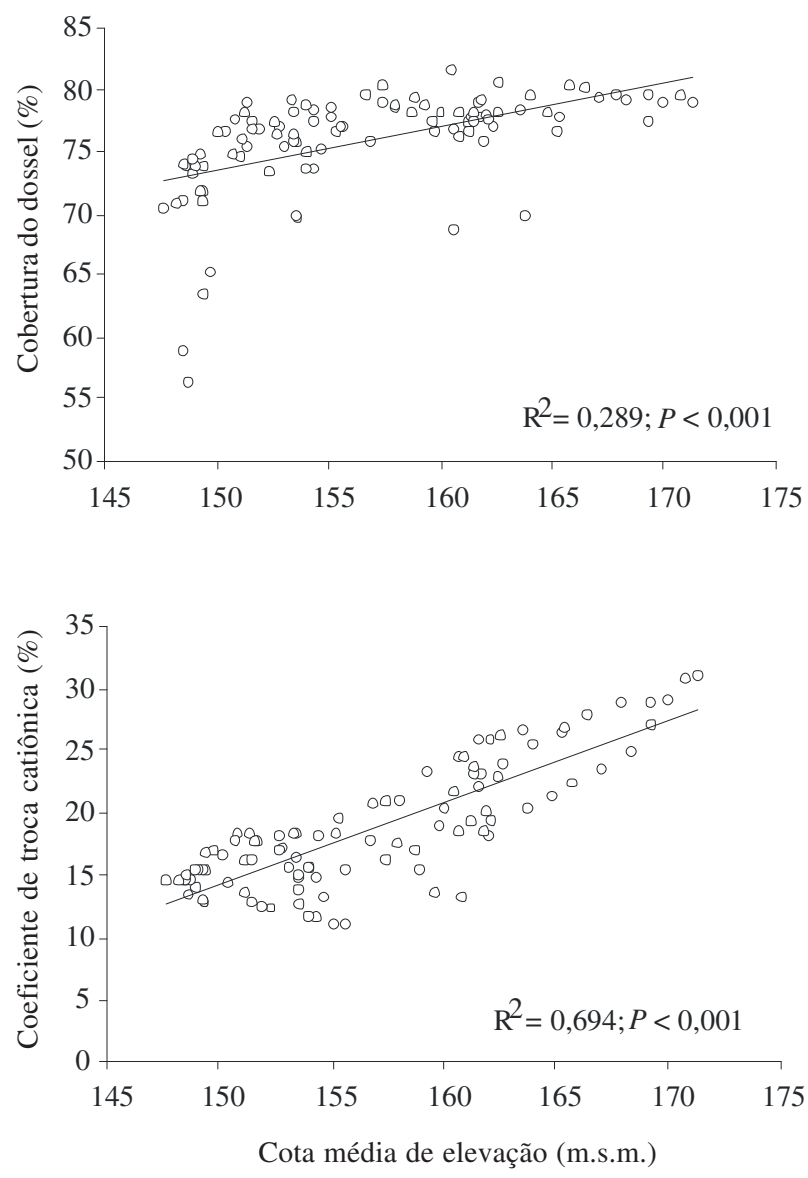

Figura 3. Regressões lineares entre a cota média de elevação das unidades amostrais e outras variáveis ambientais, em uma floresta ribeirinha do rio Uruguai, sul do Brasil. 


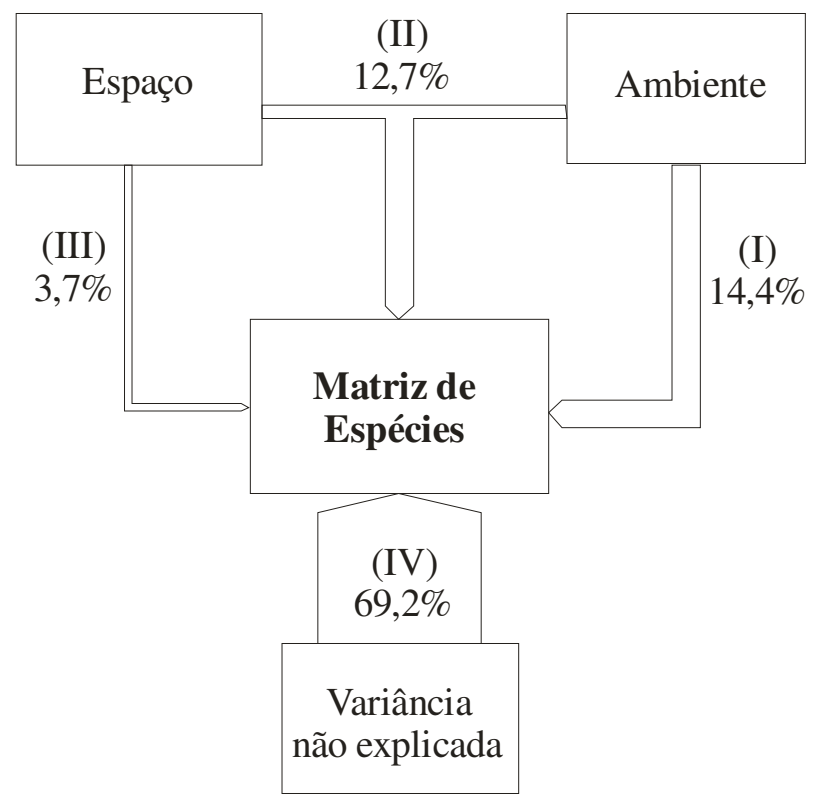

Figura 4. Porcentagens da variação na matriz de espécies explicadas por variáveis ambientais (I), pela estrutura espacial compartilhada entre espécies e variáveis (II) e pela autocorrelação espacial das espécies (III), em uma floresta ribeirinha do rio Uruguai, sul do Brasil. Adicionalmente é mostrada a fração de variação não atribuível às variáveis ambientais e espaciais amostradas (IV).

ambientais (fração II), o que é uma adição relevante ao modelo, pois a AE costuma ser mensurada apenas por meio de métodos complexos e trabalhosos (e.g., " $\Gamma$ " de Moran, " $c$ " de Geary, semivariogramas; q.v. discussão em Dale et al. 2002), limitando sua utilidade para o estudo de comunidades, além de contrastar com a ocorrência ampla do fenômeno (Legendre 1993) e sua relevância na modelagem de ambientes (Titeux et al. 2004).

A fração IV representa a variação na matriz de espécies não previsível através das variáveis ambientais mensuradas e incluídas no modelo. Esta variação é atribuída a flutuações estocásticas e a variáveis não mensuradas (Borcard et al. 1992) ou ao fato de que nem todos os sítios favoráveis são ocupados pelas respectivas espécies (Titeux et al. 2004). Dentre as variáveis não mensuradas, constam aquelas referentes ao histórico da área, que para ambientes ribeirinhos podem ser representadas por enchentes de grande magnitude ou queda de árvores por fatores como vendavais ou, ainda, incêndios (Naiman et al. 1998), de modo que o efeito destas pode ficar parcialmente incluído na fração II, caso as variáveis ambientais também tenham sido afetadas (Borcard et al. 2002). Eventos históricos formam clareiras, que são variáveis no espaço e no tempo (Augspurger 1983), mas cujas localizações pretéritas são quase sempre indisponíveis. Além disso, a distribuição de diásporos pode ser heterogênea, principalmente para espécies zoocóricas, neste caso devido ao comporta- mento animal e não à predileção planta-ambiente (Schupp et al. 2002). Johansson et al. (1996) utilizaram a capacidade de flutuação dos diásporos, como definidora do tipo de dispersão, e encontraram correlação com o zoneamento da vegetação. Por outro lado, erros implícitos, por exemplo, na interpolação das variáveis químicas e físicas, reduzem a relação final encontrada entre as matrizes.

Variações estruturais - A análise de agrupamento se baseou na variável 'Cota', devido ao fato das demais serem correlatas, e resultou num valor $k=3$, determinando três grupos de UAs. Porém, como a influência de 'Cota' sobre a vegetação é indireta, optou-se subjetivamente por considerar os grupos formados como característicos de diferentes suscetibilidades à inundação. Assim, o primeiro grupo de parcelas foi associado a inundações freqüentes, o segundo a inundações eventuais e o terceiro a inundações muito raras. Os três grupos apresentaram diferenças significativas para parâmetros estruturais e para o índice de Shannon, não sendo diferentes para a equabilidade de Pielou. As medianas dos parâmetros estruturais e índices de diversidade por UAs agrupadas em diferentes classes de inundação (CI) constituem a Tab. 3.

As UAs da CI-2 (suscetíveis a inundações frequientes) apresentaram as medianas mais elevadas para a 'média de perfilhamentos por indivíduo' e para o 'número de ramos', além das menores medianas para a 'altura máxima' e 'área basal'. A diminuição do porte da comunidade foi constatada por Ernst \& Brooks (2003) após a elevação da freqüência de inundações em uma floresta, resultante de modificações regionais no uso do solo, embora os mesmos autores tenham constatado diminuição concomitante no número de ramos por área. Eventualmente, este resultado pode estar relacionado com as altas mortalidades também assinaladas pelos mesmos e que denotam uma comunidade em reestruturação, em função da modificação do regime de inundações. A baixa altura da vegetação da CI-2 resulta em estratificação pouco evidente (não existindo dossel florestal típico e, portanto, sem sub-bosque), contrastando com as UAs adjacentes da CI-1.

As UAs da CI-1 apresentaram as medianas mais elevadas para 'altura máxima', 'área basal', 'número de indivíduos', 'riqueza específica' e 'índice de Shannon'. Pollock et al. (1998) encontraram resultados semelhantes em relação à riqueza, a qual foi relacionada também a áreas com maior produtividade e heterogeneidade espacial no ambiente físico. Vários trabalhos têm comprovado a eficiência do "modelo de equilíbrio dinâmico" de Huston (Pollock et al. 1998), que define a adição de um regime de distúrbios com freqüência, recorrência e magnitude moderadas (apesar 
Tabela 3. Medianas de parâmetros estruturais e índices de diversidade para unidades amostrais, agrupadas de acordo com diferentes cotas médias de elevação, de uma floresta ribeirinha do rio Uruguai, sul do Brasil. P: probabilidade resultante do teste Kruskal-Wallis. Letras diferentes após números indicam diferenças em testes pareados de Dunn; letras iguais indicam valores indistintos. CI-2 (30 UAs): inundações freqüentes; CI-1 (31 UAs): inundações eventuais; CI-0 (39 UAs): inundações raras.

\begin{tabular}{|c|c|c|c|c|}
\hline Parâmetros estruturais & $\mathrm{CI}-2$ & CI-1 & $\mathrm{CI}-0$ & $P$ \\
\hline Número de indivíduos (ind. UA ${ }^{-1}$ ) & $19,5^{\mathrm{a}}$ & $20^{\mathrm{a}}$ & $11^{\mathrm{b}}$ & $<0,001$ \\
\hline Número médio de perfilhamentos (perf. ind. ${ }^{-1}$ ) & $2,65^{\mathrm{a}}$ & $1,207^{\mathrm{b}}$ & $1,167^{\mathrm{b}}$ & $<0,001$ \\
\hline $\operatorname{Ramos}\left(\operatorname{ramos} \mathrm{UA}^{-1}\right)$ & $40,5^{\mathrm{a}}$ & $25^{\mathrm{b}}$ & $13^{\mathrm{c}}$ & $<0,001$ \\
\hline Área basal $\left(\mathrm{m}^{2} \mathrm{UA}^{-1}\right)$ & $0,194^{\mathrm{b}}$ & $0,269^{\mathrm{a}}$ & $0,206^{\mathrm{b}}$ & $<0,001$ \\
\hline Altura máxima (m ind..$\left.^{-1} \mathrm{UA}^{-1}\right)$ & $7^{\mathrm{b}}$ & $15^{\mathrm{a}}$ & $12^{\mathrm{a}}$ & $<0,001$ \\
\hline Riqueza específica (espécies $\mathrm{UA}^{-1}$ ) & $10^{\mathrm{b}}$ & $12^{\mathrm{a}}$ & $8^{c}$ & $<0,001$ \\
\hline Índice de Shannon - H' (nats) & $2,151^{\mathrm{b}}$ & $2,303^{\mathrm{a}}$ & $1,889^{\mathrm{c}}$ & $<0,001$ \\
\hline Equabilidade de Pielou - J' & 0,931 & 0,940 & 0,939 & 0,617 \\
\hline
\end{tabular}

das diferenças, estas variáveis no restante do texto serão tratadas como "freqüência") como gerador de heterogeneidade e, assim, de maiores valores de diversidade. Idéia semelhante foi abordada por Connell (1978) e chamada de "hipótese do distúrbio intermediário". Segundo ambos modelos, áreas com distúrbios freqüentes causam inúmeras formas de estresse, reduzindo ou anulando a competitividade de espécies não tolerantes (Ernst \& Brooks 2003), e potencialmente reduzindo a riqueza específica. Um modelo adaptado às florestas ribeirinhas abordando as inundações como principal fonte de distúrbios foi desenvolvido por Tabacchi et al. (1998). Neste é proposto que a ação das inundações causa seleção de espécies, resultando em predominância de espécies pioneiras em áreas de inundações freqüentes e estabilização progressiva das comunidades em que estas são menos freqüentes. Evidências da validade deste modelo ocorrem no presente estudo, pois nos trechos com menor frequiência de inundações, a estrutura tornase mais semelhante à floresta de interflúvio na área do Parque, com a ocorrência de $S$. bonplandii (que ocorre apenas na metade mais afastada do rio) como a espécie de maior VI. Isso coincide com os resultados de Vasconcellos et al. (1992), obtido no mesmo local em área de floresta não suscetível a inundações. Contudo, maiores evidências podem ser buscadas por meio da avaliação das categorias sucessionais das espécies.

A CI-0 representa a área "madura" do modelo de Tabacchi et al. (1998), apresentando os menores valores para 'números de indivíduos', 'perfilhamentos', 'área basal', 'riqueza de espécies' e 'índice de Shannon' por UA. A diminuição da quantidade de espécies é esperada, segundo o modelo, devido ao aumento da dominância por espécies competitivamente "superiores" (Connell 1978).

A partir dos resultados do presente estudo se conclui que existe um gradiente vegetacional evidente na área, que está relacionado com a cota de elevação e, assim, com a suscetibilidade à inundação dos diferentes sítios. Além disso, diversas variáveis ambientais puderam ser arranjadas de forma hierárquica para explicar as diferenças vegetacionais encontradas. Parâmetros estruturais, tais como a área basal e altura máxima, bem como a riqueza de espécies e a diversidade de Shannon, possuem valores mais elevados nas áreas com suscetibilidade intermediária à inundação. Já as áreas mais baixas são distintas estruturalmente pela ausência de "dossel florestal típico" em virtude de diferenças na composição florística atribuídas à seletividade causada pelas inundações frequientes. Finalmente, a decomposição da variação na matriz de espécies e de variáveis ambientais assinalou a presença de leve autocorrelação espacial.

\section{Agradecimentos}

À Fundação O Boticário pelo financiamento (projeto 0695/20061); à CAPES e ao CNPq pelas bolsas concedidas; à Secretaria Estadual do Meio Ambiente (DUC/DEFAP/SEMA) pela autorização e pela concessão de alojamento na área de estudo; aos guardas-parque do Parque Estadual do Turvo pelos inúmeros auxílios; a Adriana Leonhardt e Jean Carlos Budke pela revisão do manuscrito; ao professor Michael Palmer pelo auxílio com a análise de peculiaridades na CCA.

\section{Referências bibliográficas}

ANA - Agência Nacional das Águas. 2006. HidroWeb: Sistema de Informações Hidrológicas. Disponível on-line em http:// hidroweb.ana.gov.br/. (Acessado em 24/07/2006).

APGII - Angiosperm Phylogeny Group. 2003. An update of the Angiosperm Phylogeny Group classification for the orders and families of flowering plants. Botanical Journal of the Linnean Society 141: 399-436.

Augspurger, C.K. 1983. Seed dispersal of the tropical tree, Platypodium elegans, and the escape of its seedlings from fungal pathogens. Journal of Ecology 71: 759-771. 
Bertani, D.F.; Rodrigues, R.R.; Batista, J.L.F.; Shepherd, G.J. 2001. Análise temporal da heterogeneidade florística e estrutural em uma floresta ribeirinha. Revista Brasileira de Botânica 24: 11-23.

Bianchini, E.; Popolo, R.S.; Dias, M.C. \& Pimenta, J.A. 2003. Diversidade e estrutura de espécies arbóreas em área alagável do município de Londrina, sul do Brasil. Acta Botanica Brasilica 17: 405-419.

Blom, C.W.P.M. \& Voesenek, L.A.C.J. 1996. Flooding: the survival strategies of plants. Tree 11: 290-295.

Borcard, D.; Legendre, P. \& Drapeau, P. 1992. Partialling out the spatial component of ecological variation. Ecology 73: 1045-1055.

Botrel, R.T.; Oliveira Filho, A.T.; Rodrigues, L.A. \& Curi, N. 2002. Influência do solo e topografia sobre as variações da composição florística e estrutura da comunidade arbóreo-arbustiva de uma floresta estacional semidecidual em Ingaí, MG. Revista Brasileira de Botânica 25: 195-213.

Brack, P.; Bueno, R.M.; Falkenberg, D.B.; Paiva, M.R.C.; Sobral, M. \& Stehmann, J.R. 1985. Levantamento florístico do Parque Estadual do Turvo, Tenente Portela, Rio Grande do Sul, Brasil. Roessléria 7: 69-94.

Brower, J.E. \& Zar, J.H. 1984. Field and laboratory methods for general ecology. Iowa, W.C. Brown Company Publishers.

Budke, J.C.; Giehl, E.L.H.; Athayde, E.A.; Eisinger, S.M. \& Záchia, R.A. 2004. Florística e fitossociologia do componente arbóreo de uma floresta ribeirinha, Arroio Passo das Tropas, Santa Maria, RS, Brasil. Acta Botanica Brasilica 18: 581-589.

Budke, J.C.; Jarenkow, J.A. \& Oliveira Filho, A.T. 2007. Relationships between tree component structure, topography and soils of a riverside forest, Rio Botucaraí, Southern Brazil. Plant Ecology 189: $187-200$.

Cardoso, E. \& Schiavini, I. 2002. Relação entre distribuição de espécies arbóreas e topografia em um gradiente florestal na Estação Ecológica do Panga (Uberlândia, MG). Revista Brasileira de Botânica 25: 277-289.

Connell, J.H. 1978. Diversity in tropical rain forests and coral reefs. Science 199: 1302-1310.

Dale, M.R.T.; Dixon, P.; Fortin, M.J.; Legendre, P.; Myers, D.E. \& Rosenberg, M.S. 2002. Conceptual and mathematical relationships among methods for spatial analysis. Ecography 25: $558-577$.

Damasceno Junior, G.A.; Semir, J.; Santos, F.A.M. \& Leitão Filho, H.F. 2005. Structure, distribution of species and inundation in a riparian forest of Rio Paraguai, Pantanal, Brazil. Flora 200: 119-135.

Dufrêne, M. \& Legendre, P. 1997. Species assemblage and indicator species: the need for a flexible asymmetrical approach. Ecological Monographs 67: 345-366.

Ernst, K.A. \& Brooks, J.R. 2003. Prolonged flooding decreased stem diversity, tree size and shifted composition towards clonal species in a central Florida hardwood swamp. Forest Ecology and Management 173: 261-279.

Frazer, G.W.; Canham, C.D. \& Lertzman, K.P. 1999. Gap Light Analyzer (GLA): Imaging software to extract canopy structure and gap light transmission indices from true-colour fisheye photographs, users manual and program documentation. Burnaby/New York, Simon Fraser University/Institute of Ecosystem Studies.

Guisan, A. \& Zimmermann, N.E. 2000. Predictive habitat distribution models in ecology. Ecological Modelling 135: 147-186.

Hupy, J.P.; Aldrich, S.P.; Schaetzl, R.J.; Varnakovida, P.; Arima, E.Y.; Bookout, J.R.; Wiangwang, N.; Campos, A.L. \& McKnight, K.P. 2005. Mapping soils, vegetation, and landforms: an integrative physical geography experience. Professional Geographer 57: 438-451.

Ives, A.R. \& Klopper, E.D. 1997. Spatial variation in abundance created by stochastic temporal variation. Ecology 78: 1907-1913.
Jarenkow, J.A. \& Waechter, J.L. 2001. Composição, estrutura e relações florísticas do componente arbóreo de uma floresta estacional no Rio Grande do Sul, Brasil. Revista Brasileira de Botânica 24: 263-272.

Johansson, M.E.; Nilsson, C. \& Nilsson, E. 1996. Do rivers function as corridors for plant dispersal? Journal of Vegetation Science 7: 593-598.

Johnson, W.B.; Sasser, C.E. \& Gosselink, J.G. 1985. Succession of vegetation in an evolving river delta, Atchafalaya Bay, Louisiana. Journal of Ecology 73: 973-986.

Klein, R.M. 1972. Árvores nativas da floresta subtropical do Alto Uruguai. Sellowia 24: 9-62.

Kolb, R.M.; Medri, M.E.; Bianchini, E.; Pimenta, J.A.; Giloni, P.C. \& Correa, G.T. 1998. Anatomia ecológica de Sebastiania commersoniana (Baillon) Smith \& Downs (Euphorbiaceae) submetida ao alagamento. Revista Brasileira de Botânica 21: $305-312$.

Legendre, P. 1993. Spatial autocorrelation: trouble or new paradigm? Ecology 74: 1659-1673.

Leite, P.F. 2002. Contribuição ao conhecimento fitoecológico do sul do Brasil. Ciência e Ambiente 24: 51-73.

Manly, F.J. 1991. Randomization and Monte Carlo methods in Biology. London, Chapman and Hall.

Mueller-Dombois, D. \& Ellenberg, H. 1974. Aims and methods of vegetation ecology. New York, John Wiley.

Naiman, R.J.; Fetherston, K.L.; McKay, S. J. \& Chen, J. 1998. Riparian forests. Pp. 289-323. In: R.J. Naiman \& R.E. Bilby (eds.). River ecology and management: lessons from the Pacific Coastal Ecoregion. New York, Springer-Verlag.

Naiman, R.J. \& Décamps, H. 1997. The ecology of interfaces: riparian zones. Annual Review of Ecology and Systematics 28: 621-658.

Nilsson, C. \& Svedmark, M. 2002. Basic principles and ecological consequences of changing water regimes: riparian plant communities. Environmental Management 30: 468-480.

Oliveira Filho, A.T.; Curi, N.; Vilela, E.A. \& Carvalho, D.A. 1997. Tree species distribution along soil catenas in a riverside semideciduous forest in southeastern Brazil. Flora 192: 47-64.

Oliveira Filho, A.T.; Vilela, E.A.; Carvalho, D.A. \& Gavilanes, M.L. 1994. Effects of soils and topography on the distribution of tree species in a tropical riverine Forest in south-eastern Brazil. Journal of Tropical Ecology 10: 483-508.

Perry, J.N.; Liebhold, A.M.; Rosenberg, M.S.; Dungan, J.; Miriti, M.; Jakomulska A. \& Citron-Pousty, S. 2002. Illustrations and guidelines for selecting statistical methods for quantifying spatial pattern in ecological data. Ecography 25: 578-600.

Pollock, M.M.; Naiman, R.J. \& Hanley, T.A. 1998. Plant species richness in riparian wetlands - A test of biodiversity theory. Ecology 79: 94-105.

Rambo, B. 1935. La vegetación del Alto Uruguay. Revista Sudamericana de Botánica 2: 108-110.

Rambo, B. 1961. Migration routes of the South Brazilian rain forest. Pesquisas, Série Botânica 12: 1-54.

Reitz, R.; Klein, R.M. \& Reis, A. 1983. Projeto Madeira do Rio Grande do Sul. Sellowia 34-35: 1-525.

Richards, K.; Brasington, J. \& Hughes, F. 2002. Geomorphic dynamics of floodplains: ecological implications and a potential modelling strategy. Freshwater Biology 47: 559-579.

Ritchie, J.; Nearing, M.A.; Nichols, M.H. \& Ritchie, C.A. 2005. Patterns of soil erosion and redeposition on Lucky Hills Watershed, Walnut Gulch Experimental Watershed, Arizona. Catena 61: 122-130.

Rodrigues. R.R. \& Nave, A.G. 2001. Heterogeneidade florística das matas ciliares. Pp. 45-71. In: R.R. Rodrigues \& H.F. Leitão Filho (eds.). Matas ciliares: conservação e recuperação. São Paulo, Universidade de São Paulo.

Rodrigues, R.R. \& Shepherd, G.J. 2001. Fatores condicionantes da vegetação ciliar. Pp. 101-107. In: R.R. Rodrigues \& H.F. Leitão Filho (eds). Matas ciliares: conservação e recuperação. São Paulo, Universidade de São Paulo. 
Rodrigues, R.R. 2001. Florestas ciliares? Uma discussão nomenclatural das formações ciliares. Pp. 91-99. In: R.R. Rodrigues \& H.F Leitão Filho (eds.). Matas ciliares: conservação e recuperação. São Paulo, Universidade de São Paulo.

Rosales, J.; Petts, G. \& Knab-Vispo, C. 2001. Ecological gradients within the riparian forests of the lower Caura River, Venezuela. Plant Ecology 152: 101-118.

Schupp, E.W.; Milleron, T. \& Russo, S. 2002. Dissemination limitation and the origin and maintenance of species-rich tropical forests. Pp. 19-33. In: D.J. Levey; W.R. Silva \& M. Galleti (eds.). Seed dispersal and frugivory: ecology, evolution and conservation. New York, CABI Publishing.

SEMA - Secretaria do Meio Ambiente. 2005. Plano de manejo do Parque Estadual do Turvo. Porto Alegre, Divisão de Unidades de Conservação do Estado do Rio Grande do Sul.

Shepherd, G.J. 2006. FitopacShell 1.6: manual do usuário. Campinas, Departamento de Botânica.

Sobral, M.; Jarenkow, J.A.; Brack, P.; Irgang, B.; Larocca, J. \& Rodrigues, R.S. 2006. Flora arbórea e arborescente do Rio Grande do Sul, Brasil. São Carlos, RiMA/Novo Ambiente.

Sollins, P. 1998. Factors influencing species composition in tropical lowland rain forest: does soil matter? Ecology 79: 23-30.

Suzuki, W.; Osumi, K.; Masaki, T.; Takahashi, K.; Daimaru, H. \& Hoshizaki, K. 2002. Disturbance regimes and community structures of a riparian and an adjacent terrace stand in the Kanumazawa Riparian Research Forest, northern Japan. Forest Ecology and Management 157: 285-301.
Tabacchi, E.; Correl, D.L.; Hauer, R.; Pinay, G.; Planty-Tabacchi, A. \& Wissmar, R.C. 1998. Development, maintenance and role of riparian vegetation in the river landscape. Freshwater Biology 40: 497-516.

Tedesco, M.J.; Gianello, C.; Bissani, C.A.; Bohnem, H. \& Volkweiss, S.J. 1997. Análise de solo, plantas e outros materiais. Porto Alegre, UFRGS

ter Braak, C.J.F \& Šmilauer, P. 2002. Canoco for Windows 4.5 Wageningen, Biometris/Plant Research International.

ter Braak, C.J.F. 1988. The analysis of vegetation-environment relationships by canonical correspondence analysis. Vegetatio 69: 69-77.

Titeux, N.; Dufrêne, M.; Jacob, J.; Paquay, M. \& Defourny, P. 2004. Multivariate analysis of a fine-scale breeding bird atlas using a geographical information system and partial canonical correspondence analysis: environmental and spatial effects. Journal of Biogeography 31: 1841-1856.

Tomé Jr., J.B. 1997. Manual para interpretação de análise de solo. Guaíba, Agropecuária.

van den Berg, E. \& Oliveira-Filho, A.T. 1999. Spatial partitioning among tree species within an area of tropical montane gallery forest in south-easthern Brasil. Flora 194: 249-266.

van Schaik, C.P. \& Mirmanto, E. 1985. Spatial variation in the structure and litterfall of a Sumatran rain forest. Biotropica 17: $196-205$

Vasconcellos, J.M.O.; Dias, L.L.; Silva, C.P. \& Sobral, M. 1992. Fitossociologia de uma área de mata subtropical no Parque Estadual do Turvo, RS. Revista do Instituto Florestal 4: 252-259. 